\title{
Differential Diagnosis of Thyrotoxic Myopathy
}

\author{
Valery Kazakov ${ }^{1,2^{*}}$, Alexander Skoromets ${ }^{1}$, Tima Stuchevskaya ${ }^{1.2}$, Dmitry Rudenko ${ }^{1,2}$, Vladislav \\ Kolynin ${ }^{1,2}$
}

${ }^{1}$ Department of Neurology, First Pavlov State Medical University, St. Petersburg, Russia

${ }^{2}$ Neuromuscular Unit, City Hospital 2, St. Petersburg, Russia

Email: *valerykazakov@mail.ru

How to cite this paper: Kazakov, V., Skoromets A., Stuchevskaya, T., Rudenko, D. and Kolynin, V. (2017) Differential Diagnosis of Thyrotoxic Myopathy. Open Journal of Molecular and Integrative Physiology, 7, 25-33.

https://doi.org/10.4236/ojmip.2017.72002

Received: April 14, 2017

Accepted: May 28, 2017

Published: May 31, 2017

Copyright $\odot 2017$ by authors and Scientific Research Publishing Inc. This work is licensed under the Creative Commons Attribution-NonCommercial International License (CC BY-NC 4.0). http://creativecommons.org/licenses/by-nc/4.0/ (c) (i) \&) Open Access

\begin{abstract}
Along with hereditary myopathies, there are many exogenic (the same a not hereditary) muscle affections due to the pathology of endocrine gland's functioning. These forms of muscle pathology are called endocrine myopathies. In the cases of thyroid gland hyperfunction (the same a thyrotoxicosis), different regions of neuromuscular system may be involved in the pathological process. Thyrotoxic myopathy (TM) which is a subject of this investigation, occupies one of the first places between thyrotoxic (the same a thyrotoxicosis) neuromuscular affections. Meanwhile, for a long time in literature there was no clarity about the degree of muscle weakness and atrophy to diagnose TM in a patient. It's because of the fact that the majority of patients complain of increased fatigue and general weakness due to thyrotoxicosis. In present time TM diagnostics is very rare. TM is a phenocopy (the clinical similar) of many neuromuscular diseases. However in literature, the data about peculiarities of clinical picture of TM is almost completely absent, it isn't known about the frequency of affection of the isolated muscles or muscle groups, the topography of muscle weakness and successive involvement of isolated muscles in the pathological process during different stages of thyrotoxicosis and myopathy. The questions of differential diagnosis with similar neuromuscular disorders are described very poorly. In present article, we accent our attention at the clinical differentiation of the TM with other neuromuscular diseases, namely muscular dystrophy, myasthenia gravis, polymyositis, Addison's disease, proximal spinal muscular atrophy, steroid myopathy and neurosis. In our opinion, the early diagnosis of TM may help the diagnosis of thyrotoxicosis in patients who have no classical clinical signs of this disease, i.e. in patients with latent thyrotoxicosis.
\end{abstract}

\section{Keywords}

Thyrotoxicosis, Thyrotoxic Myopathy (Myopathy Due to Thyrotoxicosis), Specific Pattern of Muscle Involvement in Thyrotoxic Myopathy, Differential Diagnosis 


\section{Introduction}

Side by side with hereditary types of myopathy, there is a special class of muscular affections that were influenced by the disturbances of endocrine glands. Thyrotoxic (the same a thyrotoxicosis) myopathy (TM) is found oftener than the other thyroid neuromuscular disease (encephalomyelopathy (simultaneously affection of brain and spinal cord), polyneuropathy, exophthalmic ophthalmoplegia (In ophthalmic Graves' disease, the commonest of exophthalmic ophthalmoplegia-Bannister R. Brain and Bannister's Clinical Neurology, 7 Ed., Oxford 1992, p.53), hypokalemic paralysis, myasthenia syndrome, syndrome amyotrophic lateral sclerosis (syndrome ALS), cerebellar ataxia). In 1938, TM was picked out as an independent nosological type [1] (In 1938, Brain and Turnbull intheir classification of muscle affections by thyrotoxicosis described thyrotoxic myopathy acute and chronic forms). At present, TM is diagnosed very seldom, which is the result of the fact that doctors-practitioners do not often come across this clinical picture of the disease. There is an opinion as well as if the thyrotoxicosis weakness is always affected by common asthenia and not by the affection of the skeletal muscles. There are some objective reasons that make the diagnosis of TM difficult. They are: relatively light affection of separate muscles, absence of paralysis (there are rare exception); disguise of myopathy with the symptoms of the thyrotoxicosis and corresponding complaints of patients. As a rule, TM patients do not complain on muscular weakness and explain difficulties when moving with the help of some other reasons (leanness, overstrain, age, "lay by salt", etc.). What makes the diagnosis more difficult is the absence of muscle atrophy and muscles look "healthy" often.

All said is the reason of the fact that the research of neuromuscular system of patients having TM does not take place and myopathy is not diagnosed. Meanwhile if to arrange a special clinical research it can distinguish $61 \%-81.5 \%$, if to use electromyography, $92.6 \%-100 \%$ of TM patients can be picked out [2] [3] [4] [5] [6].

\section{Material and Method}

We studied the results of research of 263 TM patients, 47 men and 216 women (151 cases of our own investigations and 112 published in medical literature). The clinical characteristic of TM patients and methods of research were described by us earlier [2] [7]. TM as well as the other endocrine muscle affections refers to the group of later myopathies. The age of the examined patients was from 16 to 70 years old (the average age 47.7 years old), the age of the patients described by some other authors was from 6 to 83 (the average age-50.3 years old). Some data say that both men and women suffer from this disease equally often [8]; some researchers say that women suffer from this disease 2.3 - 5.6 times oftener than men. The majority of TM patients have symptoms of the dis- 
ease that have been developing for 6 - 7 months since the beginning of thyrotoxicosis. The degree of the expressed myopathy does not depend on the severity and the duration of thyrotoxicosis, on the degree of increasing of thyroid gland and expressed of eyes symptoms [2] [3] [5].

A severe type of TM is managed to be diagnosed when there are well-known signs of thyrotoxicosis increasing of thyroid gland, exophthalmos and tachycardia). Real difficulties arise in cases when thyrotoxicosis develops latently and the patient did not have any goiter and exophthalmos. In this situation the appearance of muscular affections could be considered as a neuromuscular disease that is not connected with thyrotoxicosis. It is considerable difficult represent to diagnose a light degree of myopathy, especially at elderly people: the appearance of weakness and atrophy can be considered as age changes. There is opinion [6] [9] that if an elderly man has a progressive muscular weakness, which is difficult to explain, and atrophy againsta background of total leanness, than we can suppose that it is polymyositis may be of paraneoplastic nature.

According to the clinical data and morphological changes in muscles and electromyography as well TM is a phenocopy (the clinical similar) of some hereditary and unhereditary (not hereditary) neuromuscular diseases. It is very important to distinguish this exogenous myopathy from similar diseases as the treatment leads to almost a complete regress of TM; consequently timely diagnosis is vitally necessary. In cases when special treatment of TM is not done, the muscular weakness increases, the patient cannot move by himself (the same an independent). Very severe changes weakness of bulbar [10] [11], breathing and diaphragm muscles can be seen at some patients [12]. Some patients of death from TM are described.

\section{Results and Discussion}

A group of diseases with which it is necessary to differentiate TM is defined with the degree of its expressiveness. Severe types with the expressed atrophy of muscles it is necessary to distinguish from muscular dystrophies, paraneoplastic myopathy, proximal spinal muscular atrophy and diabetic proximal amyotrophy (atrophy proximal muscles); when we mention bulbar affections we should distinguish it from polymyositis, Addison's disease and steroid myopathy.

We can find out phenotypically similarity of TM with limb-girdle variants of muscular dystrophy [2] [3] [7]. However complaints of patients having muscular dystrophy of the muscle weakness and moving changes affected by it are leading ones here, there as in TM patients predominate of the "thyrotoxic complaints" (However in patients with muscular dystrophy the complaints as a rule connected with muscle weakness and motor disturbances, but in TM patients predominate of the "thyrotoxic complaints" (the classical complaints which characteristic for thyrotoxicosis). We would like to add to this that the hereditary type of muscular dystrophy develops very slowly, for a period of some years, whereas myopathic (the weakness of definite muscles) signs at patients having TM arise 
considerably quicker-for a period of some months (or weeks). The iliopsoas and gluteus maximus muscles are involved early in the process of these both diseases. However, in TM patients, as a rule, at the same time discover a weakness in the intercostals volaris and lumbricales (interossei palmaris and lumbricales) muscles and (or) a flexors of the neck; but in patients with muscular dystrophy the function of these muscles are spare even in the late stage of the disease. One can see changes in the further generalization of muscle affections. When a patient has a hereditary muscular dystrophy he early feels weakness of quadriceps femoris and gluteus medius muscles as well as interscapular (trapezius, serratus anterior) muscles. The patients fall very often (the weakness of quadriceps femoris muscles), moving from side to side-duck walk (the weakness of gluteus medius muscles), it is difficult for them to rise arms higher than head (the weakness of trapezius and serratus anterior muscles). Because of the considerate changes of muscle balance different strong deformations of skeleton appear (increasing of lumbar lordosis, sharp displacement of shoulders girdle downwards and forwards, musculi pectorals major completely lost, "sunken" chest, flexion of the forearms possible only at the expense of the round pronator, and the flexion of the hand and fingers, wing-like shoulder-blades-"the winging of the scapula" or "scapula alatae (alate)". TM patients do not have changes mentioned above. The majority of muscles including iliopsoas muscles are being affected in a light or moderate degree (the force is 3 ball and higher). When the disease progresses the degree of muscle strength does not become lower than 3 balls excluding the gluteus maximus muscles and rectus and obliques (internal and external) abdominis as well.

In patients having muscular dystrophy feel weakness of muscles that comes after atrophy (excluding pseudohypertrophic muscles are exceptions). TM patients have "weak" muscles that keep very often normal volume and muscle being atrophied keeps muscular force in a considerable degree. Such disproportion between the degree of weakness and atrophy of muscles is a very important sign of TM. To our mind, the disappearance of subcutaneous fatty tissue created false impression of severe atrophy of the muscle. With this fact, it is connected with another important clinical sign. This is extraordinary skin folding in the field of the muscle that was affected, especially the triceps brachii and quadriceps femoris muscles. It was these muscles that keep the full strength but seems to be most atrophied. Patients suffering of muscular dystrophy do not have the phenomenon of considerate skin folding above the muscle that was affected been if there is no muscular venter at all. It is necessary to add that deep reflexes in patients with muscular dystrophy lessen very early and disappear were as they remain normal or increase at TM patients.

Some TM patients have weakness of proximal and distal muscles and simultaneously bulbar muscles are found to be affected [8] [10] [11]. In these cases it is necessary to differentiate TM not only with muscular dystrophy (oculopharengeal (oculopharyngeal) form) but as well with proximal spinal muscular 
atrophy (PSMA) [13]. PSMA begins with the affection of pelvic girdle and hips muscles, then shoulder girdle and upper arm are involved in the process; in the later period the distal parts of legs and arms muscles and the $5^{\text {th }}, 7^{\text {th }}, 9^{\text {th }}-12^{\text {th }}$ nuclei of cranial nerves are being affected. Light dysphagia, nasalalya (nasalize) and dysarthria arise; one can observe fasciculations in face, tongue, limbs and body muscles. Unlike TM patients with PSMA have weakness and atrophy of mimic and chewing muscles including the tongue muscle as well. Atrophy and weakness of hips muscles including the quadriceps muscles arise very early. The affection of distal parts of the limbs is severe: side by side with atrophy and weakness of little wrists muscles (especially thenar and hypothenar eminences) the expressed weakness of extensors and flexors of wrists and feet is being exposed. At TM patients only adductors muscles of the wrists fingers are affected to some light or moderate degree, and muscle weakness predominate at atrophy. Presence of fasciculations witnesses very convincingly against TM. Pyramidal tract affection in TM patients occurs very rarely [14].

Great difficulties arise to differentiate of TM and idiopathic polymyositis [15]. There is some clinical similarity between these two diseases: expressed general leanness and increasing muscular weakness; early involvement of flexors of neck and pelvic girdle muscles; prevailed of muscular weakness over the degree of atrophy, hypercreatinuria (creatinuria). In patients with polymyositis described the increase of the main metabolism. Muscular weakness is developing more in case of polymyositis unlike of TM: side by side with proximal parts the distal parts of the limbs are rather often involved in the process. Flexors and extensors of wrists and feet can be affected at a very early stage and very severely. Unlike from TM, atrophied muscles are always weak. There is never extraordinary skin folding in the field of the affected muscle. In polymyositis patients have very often changes in the configuration of joints; one can mention arthralgia, painfulness of tendons, changes on skin and phenomenon of Reyno (by French-Reneau) [16].

The investigation of thyroid gland function (level of thyroid hormones in blood, antibodies in thyroglobulin and thyroid peroxidase, level absorption of radioactive isotope $\mathrm{I}^{131}$ of thyroid gland) is of great differential diagnostic significance and helps either to support or reject the diagnosis of TM. The study of creatinkinase (creatine kinase) level, antinuclear and Jo-1 antibodies in blood and electromyogram will be useful as well.

If with the help of regular research methods it is impossible to diagnose of thyrotoxicosis and the clinical data witness in favour of TM, then ex juvantibus can be prescribed methylthiouracil with the next definition of creation level in whole day urine. If big doses of methylthiouracil ( $80 \mathrm{gr} /$ day) are prescribed to TM patients they arise considerable decrease or disappearance of creatinuria during several days [17]. If there are hints that the patients have polymyositis prednisolone can be prescribed. It should be taken every day $(1 \mathrm{or} 1.5 \mathrm{mg} / 1 \mathrm{~kg}$ of the weight) and it will lead to a considerate decrease of muscular weakness dur- 
ing 2 - 4 weeks. Special diagnostic difficulties arise in cases when in the patients with the symptoms of light TM the polymyositis is developing. The absence of the regress of myopathy when euthyroid state is achieved (according to clinical and laboratory data) as a result of taking antithyroid drugs will witness in favour of polymyositis.

As we marked, one of the clinical peculiarities of TM can be considered predominate of weakness over atrophy of certain muscles, presence of a typical "formula" of muscle affections (weakness) in the early and latent phase of the disease. This differs TM from Addison's disease: at the latter one can mark progressive fatiguability transferring into a sharp general adinamia but at TM patients weakness is combined with motor excitation, lively facial expression and gesticulation. Another important signs of Addison's disease are skin hyperpigmentation, painful spasms of the belly muscles, painful flexor muscular contractures, provoked by the affection of tendons and ligaments.

The clinical signs of muscular affections arising at steroid therapy may remain similar signs TM has. We observed some patients who had weakness and atrophy of pelvic girdle and hip muscles against the background of treatment by prednisolone in case of collagenous disease [2]. By the moment of development of muscle affections all these patients had features of Cushing syndrome. Rather often one could find dark red stripes on the abdomen and hips, painfulness of muscles while palpation. Muscular atrophy was more expressed than at TM patients. Simultaneously with the changes of pelvic girdle muscles one could expose considerable atrophy and weakness of muscles of lower arm and wrists. Mixed changes (myogenic and neurogenic) were fixed at electromyograms. After abolishing to take hormones the regress of myopathy was marked.

The level of sugar in blood can be increased at thyrotoxic patients. Sometimes the development of thyrotoxicosis could be complicated with the joining of sugar diabetes. At the same time sugar diabetes patients are known to have weakness and atrophy of muscles of proximal parts of extremities especially of legs and pelvic girdle muscles. Such affections got the name of proximal diabetics amyotrophy (atrophy proximal muscles). Unlike from TM very often one can expose asymmetry of muscular affections, involvement of distal parts of extremities in the process, myalgia (lumbalgia, ischialgia), lumboischialgia, paresthesia, light affections of sensitivity in wrists and feet.

Pathological muscular fatiguability and weakness are characteristic signs of severe myasthenia. This disease differs from TM by some clinical peculiarities. Muscular weakness at TM patients constant by its character carries away only certain muscles. When a patient has myasthenia his muscular weakness is more generalized and increases under a very little physical load to a degree when it becomes impossible to carry out physical job. This is the reason of variation of expressiveness of different symptoms during a day. The characteristic features of myasthenia are ptosis, diplopia and restricted movements of eyes balls upwards and outwards, dysarthria, dysphagia, dysphonia and amimiya (the same-absent 
facial expression). TM can be complicated by the weakness of bulbar muscles. However we cannot expose in TM the weakness of the external eyes muscles and "dropping" of the lower jaw as well because of the expressed weakness of the chewing muscles (mm. masseters).

Combination of TM with exophthalmic ophthalmoplegia is observed seldom [2] [3]. Severe affection of mimic muscles is a very rare phenomenon as well. In TM patients after taking anticholinesterase drugs do not feel the increase of facial muscle strength as well as in some bulbar dysfunctions the regresses of symptoms after giving injections of prostygmin is absent [10] [16]. However anti thyroid therapy comes to a complete recovery of muscular functions. The increase of muscular weakness after using tubocurarin was not observed. Introducing the anticholinesterase drugs comes rehabilitate the size of potentials amplitude to the normal. Such electrophysiological phenomenon is not observed at the majority of TM patients [2] [3] [4] [10].

The majority of patients having thyrotoxicosis disease have the signs neuroses-like state: effective emotional instability, tears-coming, fouling or trouble, fussiness, quick psychiatric fatiguability, depression and oppression of psychics and euphoria. In connection with this one of the mostly commonly-used mistakes in differentiating TM is the diagnosis of functional disorder of nervous system. There is common opinion that very often the patients with thyrotoxic disease complain of the weakness that is the consequence of the increased fatiguability and of exhaustion of psychiatric nature (i.e. asthenia). As a result of this, there are no investigations of the state of muscular function; possibility of affected skeletal muscles in the genesis of weakness is not taken into consideration. Meanwhile at the very early stage, TM can be diagnosed using different clinical criteria [2] [3]:

1) "Formula" of distribution of muscle weakness including iliopsoas (and gluteus maximus) muscles, interosseus volaris and lumbricales (interossei palmaris and lumbricales) muscles and/or flexors of neck muscles;

2) Atrophy of triceps brachii and quadriceps femoris muscles without decreasing their strength;

3) Extraordinary skin folding above these muscles.

Complaints and anamnesis collected with this purpose, use of simple clinical tests for exposing different movement affections (getting up from the squat position and from a low chair, from the lying-on-the back position etc.) help to make it objective the presence of muscular weakness and consequently, to avoid the false diagnosis neuroses. Some regression muscular affections against the background of antithyroid therapy as seen as the function of thyroid gland is being normalized confirm TM diagnosis.

The offered criteria and first of all the peculiarities of muscle affections give the opportunity to think thyrotoxicosis disease before its clinical appearances, because TM can be in many cases the earliest sign of developing thyrotoxicosis disease. Thus muscular affections can be additional clinical criteria of early di- 
agnostics of thyrotoxicosis disease.

In terms of the using treatment of patient suffering thyrotoxic disease with the appearance of myopathy, this treatment according to the data of medical literature and our experimental study is actually a pathogenic one and its effectiveness is defined by this [2] [3] [7] [18] [19] [20] [21].

Taking into consideration the theoretical preconditions about the participation of cyclic nucleotides and $\mathrm{Ca}^{++}$in the pathogenesis of muscular weakness at TM patients [20], we should think it necessary to use medicines that increase the level of cyclic AMP in skeletal muscles (allopurinol, aminophylline, trental). For making the calcium exchange normal, it is necessary to prescribe natrium oxalate increases the ability of sarcoplasmic reticulum to accumulation calcium iones; antagonists of calcium iones (verapamil, nifedipine). After disappearance of the signs of thyrotoxicosis, it is worthwhile to repeat the periods of pathogenic treatment of myopathy (alfa-tocopherol, vitamin B-12, nerobol).

\section{Conflicts of Interests}

All authors agree with the content of the manuscript and there are no conflicts of interests between them.

\section{References}

[1] Brain, W.R. and Turnbull, H.M. (1938) Exophthalmic Ophthalmoplegia (With a Pathological Report on the Ocular Muscles and Thyroid Glands). The Quarterly Journal of Medicine, 7, 293-323.

[2] Kazakov, V.M. (1984) Thyrotoxic Myopathy (Clinical and Experimental Study). Ph.D. Thesis, First Pavlov Medical Institute of Leningrad, Leningrad. (In Russian)

[3] Kazakov V.M. (1987) Thyrotoxic Myopathy (Clinical, Diagnostic and Principal of Treatment). Journal Neurology and Psychiatry Imeni Korsakova S.S., 78, 323-330. (In Russian)

[4] Currie, S. (1981) Inflammatory Myopathies. In: Walton, J.N., Ed., Disorders of Voluntari Muscle, 4th Edition, Churchill Livingstone, Edinburgh, 525-568.

[5] Puvanendran, K., Cheah, J.S., Naganathan, N., Yeo, P.P.B. and Wong P.K. (1979) Neuromuscular Transmission in Thyrotoxicosis. Journal of the Neurological Sciences, 43, 47-57. https://doi.org/10.1016/0022-510X(79)90072-8

[6] Ramsay, I.D. (1974) Thyrotoxic Myopathy. In: Ramsay, I.D., Ed., Thyroid Diseases and Muscle Dysfunction, Willam Heinemann, London, 1-51. https://doi.org/10.1016/B978-0-433-27255-7.50007-4

[7] Kazakov, V.M., Skoromets, A.A., Kovalenko, T.M., Michailov, E.P. and Barantsevich, E.R. (1978) Chronicthyrotoxic Myopathy. Clinical and Pathogenesis. In: Il'ina, A., Ed., Molecular Basis of Pathogenesis, Principals of Diagnostic and Treatment of Neuromuscular Diseases, Medgiz, Moscow, 42-45. (In Russian)

[8] Chiu, W.-Y., Yang, Ch.-Ch., Huang, J.-Ch. and Huang, T.-S. (2004) Dysphagia as a Manifestation of Thyrotoxicosis. Report of Three Cases and Literature Review. Dysphagia, 19, 120-124. https://doi.org/10.1007/s00455-003-0510-z

[9] Walton, J.N. and Gardner-Medwin, D. (1981) Progressive Muscular Dystrophy and the Myotonic Disorders. In: Walton, J.N., Ed., Disorders of Voluntary Muscle, $4^{\text {th }}$ Edition, Churchill Livingstone, Edinburgh, 481-524. 
[10] Kammer, G.M. and Hamilton, C.R. (1974) Acute Bulbar Muscle Dysfunction and Hyperthyroidism. A Study of Four Cases and Review of the Literature. The American Journal of Medicine, 56, 464-470. https://doi.org/10.1016/0002-9343(74)90477-X

[11] Marks, P., Anderson, J. and Vincent, R. (1980) Thyrotoxic Myopathy Presenting as Dysphagia. Postgraduate Medical Journal, 56, 669-670. https://doi.org/10.1136/pgmj.56.659.669

[12] Gaan, D. (1967) Chronicthyrotoxic Myopathy with Involvement Respiratory and Bulbar Muscles. British Medical Journal, 3, 415-416. https://doi.org/10.1136/bmj.3.5562.415

[13] Kazakov, V.M., Skorometz, A.A., Kovalenko, T.M. and Mikhailov, E.P. (1977) Chronic Spinal Muscular Atrophy Simulating Facio-Scapulo-Humeral Type and Limb-Girdle Type of Muscular Dystrophy. Report of a 2 Cases. European Neurology, 16, 90-98. https://doi.org/10.1159/000114885

[14] Ravera, J.J., Cervino, J.M., Fernandez, D., Forcade, F.A., Malosetti, H, Muxi, F., et al. (1960) Two Cases of Graves' Disease with Signs of a Pyramidal Tract Lesion. Improvement in Neurological Signs during Treatment Withantithyroid Drugs. The Journal of Clinical Endocrinology \& Metabolism, 20, 876-880. https://doi.org/10.1210/jcem-20-6-876

[15] Hafeez, M., Sarfraz, T., Azhar, M., Khan, R.G. and Tarig, H. (2015) Pregnancy, Thyrotoxicosis and Polymyositis. Journal of Ayub Medical College Abbottabad, 27, 719-720.

[16] Banker, D.Q. and Engel, A.G. (1986) The Polymyositis and Dermatomyositis Stndromes. In: Engel, A.G. and Banker, B.Q., Eds., Myology Basic and Clinical, McGraw-Hill Book Company, New York, Vol. 2, 1385-1421.

[17] Bostrom, H. and Hed, R. (1958) Thyrotoxic Myopathy and Polymyositis in Elderly Patients: Differential Diagnostic Viewpoints. Acta Medica Scandinavica, 162, 225 230.

[18] Kazakov, V.M., Katinas, G.S. and Skoromets, A.A. (1986) Pathogenesis of Experimental Thyrotoxic Myopathy. European Neurology, 25, 212-234. https://doi.org/10.1159/000116011

[19] Kazakov, V.M. (1992) Terminal Intramuscular Motor Innervation and Motor end Plates in Thyrotoxic Myopathy. Neuromuscular Disorders, 2, 343-349.

[20] Kazakov, V.M., Malachovsky, V.K. Khokhlov, A.P. and Mikhaylov, E.P. (1983) Possible Importance of Impairments in the cAMP System for Pathogenesis of Thyrotoxic Myopathy. Questions Med Chimii, 29, 69-73. (In Russian)

[21] Kazakov, V.M. and Kovalenko, T.M. (1995) Experimental Thyrotoxicmtopathy. Radioautography of Protein Synthesis in Skeletal Muscles and Motor Neuron of Spinal Cord. Neuromuscular Disorders, 5, 47-52. 
Submit or recommend next manuscript to SCIRP and we will provide best service for you:

Accepting pre-submission inquiries through Email, Facebook, LinkedIn, Twitter, etc. A wide selection of journals (inclusive of 9 subjects, more than 200 journals)

Providing 24-hour high-quality service

User-friendly online submission system

Fair and swift peer-review system

Efficient typesetting and proofreading procedure

Display of the result of downloads and visits, as well as the number of cited articles Maximum dissemination of your research work

Submit your manuscript at: http://papersubmission.scirp.org/

Or contact ojmip@scirp.org 